Terrone, Enrico (2017)

"On Fictional Characters as Types",

British Journal of Aesthetics 57 (2): 161-176. 


\section{On Fictional Characters as Types}

There is a sense in which Batman in Tim Burton's film Batman and Batman in Christopher Nolan's film Batman Begins are the same fictional character. We call them both 'Batman' and this is not a case of accidental homonymy. These two characters share relevant features, and have common historical roots, since they both belong to a causal path that springs from Bob Kane's 1939 comic Batman.

On the other hand, Burton's Batman and Nolan's Batman also appear to be different fictional individuals, since they have a different look and they act in different fictional worlds. Thus, a suitable spectator of the film Batman Begins should not treat the Batman that she is seeing on the screen as the same fictional individual that she encounters while watching Burton's film Batman. If she did, she might infer that Batman has undergone a facelift, but this is not a correct inference for a suitable spectator of Batman Begins.

Thus, with respect to Batman in Burton's film and Batman in Nolan's film, we have both intuitions of sameness and intuitions of difference. There is a sense in which they are the same fictional entity and there is a sense in which they are not.

In order to reconcile these contrasting intuitions, I propose to treat fictional characters as types the tokens of which are particular individuals in particular fictional worlds (henceforth, I will use the expression 'fictional character' to designate the type and the expression 'fictional individual' to designate the token). On this proposal, Burton's Batman and Nolan's Batman are the same fictional character inasmuch as they both instantiate the BATMAN type (henceforth I will use capital letters for the name of a fictional character understood as a type), but they are different fictional individuals inasmuch as they are distinct tokens of this type.

Types allow us to reconcile intuitions of sameness and difference for a variety of entities. 
Consider two inscriptions of the word 'door'. If we treat the word as a type, we can state that (a) the two inscriptions are the same thing inasmuch as they both instantiate the same word, and yet (b) they are different things inasmuch as they are distinct inscriptions having different spatiotemporal locations. That is to say that the two inscriptions are the same at the type level but are distinct at the token level. Likewise, one can say, Burton's Batman and Nolan's Batman are the same fictional character at the type level but they are distinct fictional individuals at the token level.

The claim that fictional characters are types raises three main worries, however. First, types are usually taken to be abstract forms, eternal and unchangeable. In contrast, fictional characters are typically construed as historical outcomes of cultural practices - at least if one endorses, as I do, an 'artefactualist' or 'creationist' conception of fictional characters. ${ }^{1}$ Let us call this the creation issue.

1 Fred Kroon and Alberto Voltolini, in 'Fiction' (The Stanford Encyclopedia of Philosophy, Fall 2011 Edition, $\quad$ Nodward Zalta (ed.), URL = $<$ http://plato.stanford.edu/archives/fall2011/entries/fiction/>), characterize the core of creationism about fictional characters in the following terms: 'The intuition that story-tellers have some kind of creative role to play is accounted for by so called artifactualist, or creationist, accounts of fictional entities (see Searle (1979), Salmon (1998), Thomasson (1999), Voltolini (2006); the position was also defended in Kripke's unpublished John Locke Lectures (1973) [now published in Kripke (2013)], and elements of the position are found in van Inwagen's (1979) theory of fictional objects as posits of literary criticism; Ingarden (1931) is a significant historical forerunner). According to such accounts, fictional objects are artifacts since they come into being once they are conceived by their authors; to that extent, they are authorial creations'. The works referred to by Kroon and Voltolini in this quotation are the following: Roman Ingarden, Das Literarische Kunstwerk (Tübingen: Niemeyer, 1931); Saul Kripke, Reference and Existence (Oxford: Oxford University Press, 2013); Nathan Salmon, 'Nonexistence', Noûs 32, 3 (1998), 277-319; John R. Searle, 'The Logical Status of Fictional Discourse', in P.A. French et 
Secondly, the tokens of a type normally are concrete particulars in the actual world, as for example the inscriptions of a word, whereas the alleged tokens of a fictional character are concrete particulars in a fictional world, and therefore, unlike ordinary tokens, lack a spatiotemporal location in the actual world. Let us call this the instantiation issue. Thirdly, many fictional characters, unlike Batman, Sherlock Holmes or Hamlet, only appear in one work of fiction, and therefore, since they have a unique instance, one can wonder whether it makes sense to treat them as types. Let us call this the uniqueness issue.

The main aim of this paper is to address these issues in order to defend a creationist account of fictional characters as types, thereby exploiting the (above-mentioned) explanatory advantages which the notion of type provides us with. In other words, I will try to clarify the claim that fictional characters are abstract artefacts by arguing that such artefacts belong to the ontological category of types.

\section{The creation issue}

The creation issue can be addressed by characterizing the type as a special ontological category. This is the strategy pursued by Peter Strawson: 'The general title of 'types', often, though rather waveringly, confined to words and sentences, may well be extended. I have in mind, for example: works of art, such as musical and literary compositions, and even, in a certain sense, paintings and works of sculpture; makes of thing, e.g. makes of motor-car, such as the 1957 Cadillac, of which

al. (eds.), Contemporary Perspectives in the Philosophy of Language (Minneapolis: University of Minneapolis Press, 1979), 233-243; Amie Thomasson, Fiction and Metaphysics (Cambridge: Cambridge University Press, 1999); Peter Van Inwagen, 'Creatures of Fiction', American Philosophical Quarterly, 14 (1977), 299-308; Alberto Voltolini, How Ficta Follow Fiction. A Syncretistic Account of Fictional Entities (Dordrecht: Springer, 2006). 
there are many particular instances but which is itself a non-particular; and more generally other things of which the instances are made or produced to a certain design, and which, or some of which, bear what one is strongly inclined to call a proper name, e.g. flags such as the Union Jack.' ${ }^{2}$

From Strawson's perspective, a type is a historically established principle of construction of like particulars, which are called the type's tokens. ${ }^{3}$ A type so construed exhibits a peculiar normativity, which consists in accurately specifying how a token ought to be constructed. Thus, according to Strawson, terms such as 'table' or 'bed' do not designate types; they are nothing but predicates by means of which we can group things that share the same function but can have unrelated histories of production. ${ }^{4}$ By contrast, the tokens of a type are all members of a unique

2 Peter Strawson, Individuals (London: Methuen, 1959), 231.

3 Ibid., 233. Linda Wetzel, in her book Types and Tokens: An Essay on Universals (Cambridge: MIT Press, 2008), proposes an account of types that is more ontologically welcoming than that of Strawson. According to Wetzel, a type is any abstract entity that (1) can have instances and (2) satisfies Frege's and Quine's requirements for objectuality. Thus, in her account, biological species such as 'the Tarahumara frog' $(2008,11)$ or physical notions such as 'the electromagnetic field' $(2008,19)$ also count as types. Strawson's account of types as principles of construction of like things is narrower than Wetzel's since the former requires that a type be the outcome of some agency. One could rename the types as Strawson conceives of them with terms such as 'artefactual types' or 'pragmatic types' or 'Strawsonian types'. Still, for the sake of simplicity, in this paper I will simply call them 'types'.

4 Strawson, Individuals, 233. Ruth Garrett Millikan in On Clear and Confused Ideas: An Essay about Substance Concepts (New York: Cambridge University Press, 2000) and Crawford Elder in Real Natures and Familiar Objects (Cambridge: MIT Press, 2004) also emphasize this distinction. Millikan states that substances such as 'chair', unlike substances such as '1969 Plymouth Valiant 100', 'do not fall under well-focused substance templates' (2000, 30). Elder 
causal chain or tree, which springs from a unique principle of construction that has been established in certain historical circumstances. A type is precisely this historically created principle of construction. As Andrew Harrison puts it in his discussion of Strawson's account, types 'are not laid up in Heaven, but in cultures'.

states that ${ }^{\circ}$ Chairs are less likely to compose a copied kind than [...] Eames desk chairs of the 1957 design' $(2004,149)$. That being the case, both Millikan's notion of a well-focused substance template and Elder's notion of a copied kind have important affinities with Strawson's notion of a type, but there is also one crucial difference. What matters for falling under a Millikanian template or an Elderian kind basically is being produced through a copying mechanism or process. Thus, not only artefactual notions but also biological notions can satisfy this requirement and therefore can be treated as Millikanian templates or Elderian kinds. By contrast, Strawsonian types are principles of construction of like tokens that are rooted in the normativity of a social practice, and can therefore only have artifacts as instances.

5 Andrew Harrison, 'Works of Art and Other Cultural Objects', Proceedings of the Aristotelian Society, 68 (1967), 124. An account of types that is similar to the one Strawson and Harrison propose can be found in the following works: David Davies, 'Varying Impressions', The Journal of Aesthetics and Art Criticism, 73, 1 (2015), 81-92; ; Robert Howell, 'Types, Indicated and Initiated', The British Journal of Aesthetics, 42, 2 (2002), 105-127; Lee Walters, 'Repeatable Artworks as Created Types', The British Journal of Aesthetics, 53, 4 (2013), 461-477; Richard Wollheim, Art and its Objects: An Introduction to Aesthetics (New York: Harper and Row; 2nd edn. revised, 1980). By contrast, other philosophers are more inclined to take the term 'type' as a synonym of 'universal' and therefore introduce new expressions in order to designate the ontological specificity of the Strawsonian type. Consider, for instance: David Kaplan, 'Words', Aristotelian Society Supplementary Volume 64 (1990), 93-119; Guy Rohrbaugh, 'Artworks as Historical Individuals', European Journal of Philosophy, 11, 2 (2003), 177-205; Barry Smith, 
A Strawsonian type can function as both a principle of collection and a principle of evaluation of its tokens in virtue of being a principle of construction of these tokens. For example, we can say that a certain inscription is an incorrect instance of a poem since it contains some typos, that is: that inscription has been constructed according to the standard specified by the type (that is why it counts as a token) but it does not fully comply with that standard (that is why it counts as an incorrect token). By conceiving of the type as a principle of construction of like tokens, we can assess a certain token by considering the degree to which this token complies with the principle that governs its construction. ${ }^{6}$

Types can be created in two different ways: either directly as principles of constructions, i.e. as sets of instructions, or indirectly by means of what Strawson calls 'a model particular'. ${ }^{7}$ For example, a work of music can be created either by writing a score or by means of a paradigmatic performance (symphonies are usually created in the former way, songs in the latter).

It is worth stressing that the model particular is not itself a type. On the one hand, a type is a

'John Searle: From Speech Acts to Social Reality,' in Smith, B. (ed.), John Searle (Cambridge: Cambridge University Press, 2003), 1-33. Kaplan speaks of 'non-physical objects' having 'physical embodiment at many places and times'; Smith speaks of 'an abstract formation with a beginning, and perhaps an ending, in time'; Rohrbaugh speaks of 'a structure-preserving and transmitting mechanism which undergirds the continued life of an historical individual'. Yet, for the aim of this paper, these are mainly lexical differences, which I will neglect in what follows.

6 In this respect, types are like Wolterstorff's Platonic 'norm kinds'. Cf. Nicholas Wolterstorff, Works and Worlds of Art (Oxford: Clarendon Press, 1980), 56. The view of fictional characters as normative kinds that Wolterstorff defends in his book has, Platonism apart, some affinities with the one advocated in this paper.

7 Strawson, Individuals, 233. I owe the acknowledgement of the distinction between two ways of creating a type to a remark by the anonymous referee. 
non-particular individual, which has a beginning in time but not a place in space. On the other hand, the model particular is a full-fledged particular that has a location in both time and space. A type is a normative principle that specifies features but does not possess those features, whereas the model particular is a concrete entity that, just like other tokens, actually possesses the features specified by the type. Thus, the model particular resembles other tokens, whereas there is no resemblance relation between the type and its tokens. This is because a principle of construction does not resemble the objects the construction of which it governs. As Harrison puts it: 'The 'Form' Imperial Standard Yard, unlike the paradigm instance, cannot be of a yard in length, not indeed of any length'. 8

With this Strawsonian conception of types in place, we are well positioned to address the creativity issue for the view that fictional characters are types. Recall that the issue arises because types are supposed to be abstract and immutable entities, whereas fictional characters are clearly historically created. If nothing else, this apparent contrast suggests that fictional characters have $a$ beginning whereas types do not. If so, fictional characters cannot be types. However, Strawson's contributions in this area show that there is a legitimate notion of type that does not cast types as by definition eternal and beginning-less. Fictional characters, understood as Strawsonian types, can be created.

There is at least one class of cases in which fictional characters can be explicitly created as principles of construction of like fictional individuals: theatre. A playwright can create a certain fictional character directly as a principle of construction of like fictional individuals that can be instantiated by several actors. However, in most forms of fiction, fictional characters are normally

8 Harrison, 'Works of Art and Other Cultural Objects', 115. Beyond the debate on types, the locus classicus for this sort of reflection can be found in Ludwig Wittgenstein, Philosophical Investigations (London: Blackwell, 1953), § 50: 'There is one thing of which one can say neither that it is one metre long, nor that it is not one metre long, and that is the standard metre in Paris'. 
created by means of a model particular. In this case, normativity is acquired by means of exemplarity: the features that the model particular exhibits are the features that the future instances ought to have. Even if some features of the model particular may by more important than others, in principle any feature of the model particular has normative relevance. If some instance lacks a feature that the model particular has, one is in principle entitled to remark on this flaw and possibly ask for reasons. It is important to stress that the notion of flaw, here, is not to be interpreted from an aesthetic point of view, let alone from a moral point of view. It is just a matter of compliance with the model particular.

In the case of Batman, the model particular is to be found in issue 27 of Detective Comics, published in May 1939. In this issue the writer and artist Bob Kane (with the help of the writer Bill Finger) introduces a new character, 'the Bat-Man', which has since functioned as a principle of construction of like fictional individuals. The latter are the further instances of the type BATMAN that we can encounter in successive TV series, films or other comics such as Frank Miller's Batman: The Dark Knight Returns.

The functioning of a type such as BATMAN can be described, in abstract terms, as follows. Given a fiction-maker $A$ who introduces a fictional individual $x$ in her work of fiction, if the relevant cultural practice recognizes $x$ as being constructed by $A$ through the use of a pre-existing character $\mathrm{C}$ as principle of construction (instead of as introducing a brand-new principle of construction), then $x$ is a new instance of C. Otherwise, $x$ constitutes the original, exemplary token of a brand-new character $X$ created by $A$.

I endorse, here, the account of practices proposed by Peter Lamarque: 'The practices associated with works of all kinds are constituted by complex networks of beliefs, conventions, specialist terminology, and basic, often unstated, presuppositions. ${ }^{99}$ More specifically, I treat a

9 Peter Lamarque, Work and Object: Explorations in the Metaphysics of Art (Oxford: Oxford University Press, 2010), 10. 
cultural practice as a repository of shared information, a sort of implicit encyclopaedia that corresponds to the common knowledge of a community. From this perspective, the functioning of a type such as BATMAN can be rephrased as follows. Given a fiction-maker $A$ who introduces a fictional individual $x$ in her work of fiction, if $x$ is subsumed under a pre-existing encyclopaedia entry for a character $\mathrm{C}$, then $x$ is a new instance of $\mathrm{C}$. If, instead, a new encyclopaedia entry is expressly created for $x$ as a character, then $x$ is the model particular of a brand-new character $X$ created by $A$.

If this is right, by creating Batman, Kane did something more than just creating a particular fictional individual. He also implicitly created a principle of construction of like fictional individuals, and therefore also a standard or rule for evaluating other fictional individuals that are constructed following that principle. That is, in addition to creating Batman, he created BATMAN.

Suppose now that some children read issue 27 of Detective Comics and then start together a pretence in which one of them plays the role of Batman. The child who plays this role is supposed to take into account Batman's features as established by Kane. As such, she can be assessed by the other children with respect to the conformity of her impersonation to Kane's model particular. Thus, she can be blameworthy for failing to take on a certain feature present in the model particular. One of the other children might for example blame her by saying: 'you are wearing a red suit, but the Bat-Man's suit should be grey'.

In a similar manner, if a writer imports the character Batman into a novel, or a director imports it into a play, they are in principle exposed to the same kind of evaluation, and can be found blameworthy (or praiseworthy). It is important to stress that the notions of correctness and blameworthiness, here, are not to be interpreted from an aesthetic point of view, let alone from a moral point of view. It is just a matter of compliance with the common knowledge of a community. If the character BATMAN has certain features established by its model particular, and one creates a new instance of BATMAN that lacks some of these features, a member of the community is entitled 
to claim that this instance of BATMAN is incorrect inasmuch as it lacks such features. This claim does not involve either aesthetic or moral blame. It is just a way of signalling that this new instance deviates from the cultural norm that constitutes the character BATMAN.

For example, if one wrote a work of fiction in which Batman is a dog, one would have the right to say that this is an irregular token of Batman. Irregular, once again, does not mean aesthetically wrong or morally wrong. This just means that this instance lacks a feature of the character BATMAN. In this example, the feature 'human being' seems especially relevant, and therefore this instance of BATMAN seems especially irregular. Yet, my account is not committed to a distinction between essential and accidental features. In my view, as said above, all the features of the model particular are normative since, in principle, one member of the community can assess a new instance of a fictional character by pointing to whatever feature of the model particular and saying 'the new instance is irregular because it lacks this feature possessed by the model particular.' Whether the possession of a certain feature of the model particular is much or less relevant for the degree of correctness of a new instance is an empirical matter that goes beyond the theoretical approach of this paper.

To sum up, even if Kane, in creating Batman, did not intend to create a principle of construction of like fictional individuals but only a particular fictional individual, the features he ascribed to Batman can function as a principle of construction (and of assessment) of like fictional individuals..$^{10}$

A trait of fictional characters as types is what may be called the possibility of feedback. This is the possibility that a new instantiation of a type may end up modifying the normative content of the type instantiated. If a child plays Batman engaging in pretence with her friends, she is just instantiating BATMAN without any feedback on the normative content of that type. But if a

10 Thanks to the anonymous referee for drawing my attention to the relative autonomy of the normativity of the fictional character as a type from the fiction-maker's intentions. 
cartoonist publishes a successful new comic with Batman as its protagonist, this instantiation of BATMAN can have a significant feedback on the normative content of the type itself. This is what happened for example to Miller, whose comics not only instantiated the type BATMAN but also introduced some relevant new features of it. The features introduced by Miller's work are now part of the normative content of the type BATMAN in the disjunctive form 'if you want to instantiate BATMAN, you should comply either with Kane's specifications or with Miller's specifications'. For example, Nolan's movie Batman begins instantiates the BATMAN type by complying with Miller's specifications.

The feedback phenomenon teaches us something important about the identity conditions of the kind of types fictional characters are. For note that modifying the normative content of a type through feedback does not amount to creating a new type. The type preserves its identity, even if new normative features are added. We do not need a new encyclopaedia entry about Batman as a fictional character in order to take into account Miller's Batman. We just need to update the encyclopaedia entry that we created for Kane's Batman, by taking into account some new features. The phenomenon of feedback, from this perspective, precisely consists in an update of the encyclopaedia entry for a certain fictional character. If, instead, a new encyclopaedia entry is created, then we do no longer have a feedback on an existing character, but the creation of a brandnew character, which may have been influenced by the former character, but cannot be treated as an instance of it. ${ }^{11}$

11 I am speaking here of an ideal implicit encyclopaedia, which corresponds to the totality of the shared understandings of a certain cultural practice. However, actual encyclopaedias are often good approximations of this ideal encyclopaedia. Consider for example some excerpts of the Wikipedia entry for Batman: 'Batman is a fictional superhero appearing in American comic books published by DC Comics. The character was created by artist Bob Kane and writer Bill Finger, and first appeared in Detective Comics \#27 (May 1939). Batman's secret identity is 
As a result of the phenomenon of feedback, fictional characters as types can change over time. This consequence flows from the Strawsonian account of types as historical non-particular individuals. The changeability of a type entails that the possibility to determine its normative content is not an absolute prerogative of the model particular. Through the phenomenon of feedback, other tokens can play a similar role by establishing new features that will be henceforth specified by the type as a principle of construction of like tokens. Accordingly, to say that fictional characters are types is not to commit to their being immutable entities, as the creativity objection charges. Still, types are relatively stable entities. Changing a type requires a challenging negotiation within the cultural practice in which the type has been established as a principle of construction of like tokens. By negotiation, here, I mean an attempt to update an entry of the implicit encyclopaedia corresponding to the shared understandings of a community. In this respect, Strawsonian types are norms in force within a cultural practice, and thus resemble juridical entities such as constitutions. ${ }^{12}$

Bruce Wayne, an American billionaire, playboy, philanthropist, and owner of Wayne Enterprises. [...] Batman became popular soon after his introduction in 1939 and gained his own comic book title, Batman, the following year. As the decades went on, differing interpretations of the character emerged. The late 1960s Batman television series used a camp aesthetic, which continued to be associated with the character for years after the show ended. Various creators worked to return the character to his dark roots, culminating in 1986 with The Dark Knight Returns by Frank Miller. The success of Warner Bros.' live-action Batman feature films have helped maintain public interest in the character'. Thanks to the anonymous referee for leading me to reflect in more depth on the source of the types' normativity. The notions of 'ideal encyclopedia' and 'feedback' are the results of such a reflection.

12 Thomasson draws on the analogy between fictional characters and abstract artifacts such as laws of state; see Fiction and Metaphysics, 130. Likewise, Luke Manning treats fictional characters as 'constitutive rules'; see his 'Real Representation of Fictional Objects', The Journal of Aesthetics 
Just as the latter, the former can be supplemented with new normative contents without losing their identity. Just as a constitution can be supplemented with new amendments while remaining the same constitution, so a fictional character (as a type) can be supplemented with new versions (i.e. new clusters of features that are established by the phenomenon of feedback), while remaining the same fictional character. And just as constitutions are in practice typically relatively stable, and amendments relatively rare, so it typically is with fictional characters. The identity of the fictional character across changes, just as that of a constitution, is warranted by the shared understandings of the relevant cultural practice.

\section{The instantiation issue}

The poem-type The Wild Swans at Coole can be instantiated by a token that is an inscription. The flag-type Union Jack can be instantiated by a token that is a coloured surface. Both inscriptions and coloured surfaces are concrete particulars in the actual world. But the tokens of a fictional character such as BATMAN cannot be concrete particulars in the actual world. Certainly, in the actual world, there are inscriptions and coloured surfaces that support the instantiation of BATMAN, but those inscriptions and surfaces are not tokens of the type BATMAN. This is because the type in question is a principle of construction of like fictional individuals, rather than a principle of construction of like inscriptions or of like coloured surfaces. What the type BATMAN specifies are the features of a fictional person, and a token that exhibits these features should be a fictional person.

Here is the specificity of fictional characters with respect to ordinary types such as poems or flags: the tokens of a fictional character cannot be concrete particulars in the actual world. This specificity raises the issue of the instantiation of fictional characters. What exactly are the tokens of

and Art Criticism, 72 (2014), 13-24. The account of fictional characters I propose is sympathetic with Thomasson's and Manning's views but differs from them inasmuch as I claim that the normativity of fictional characters is connected to their nature of types. 
such types? How can there be a type which is created in the actual world but whose tokens are not in the actual world? How can we apply a principle of construction of like tokens if the entity to be constructed is not in the actual world?

I suggest that these questions can be addressed by means of the notion of a mental file, understood as a mental particular that functions as a vehicle of singular thought, i.e. as 'a repository of information that the agent takes to be about a single individual'. ${ }^{13}$ The instantiation of a fictional character cannot produce a fictional person in the actual world, but it can nevertheless produce a mental file in the mind of the suitable recipient of a certain work of fiction. And this file purports to refer to an individual in the fictional world who should exhibit the features specified by the type as a principle of construction of fictional individuals. Thus, the fictional character actually is instantiated by a mental file, which allows the suitable recipient of a work of fiction to purport to refer to the fictional individual that constitutes the token of the fictional character understood as a type. Fictional characters, so understood, are peculiar types, which lack actual tokens but nevertheless have actual instances, namely mental files, which purport to refer to the individuals exhibiting the features specified by the types, namely the purported tokens.

I am drawing here on a subtle distinction between tokens and instances of a type. By 'token' I mean something that exhibits the features specified by the type while by 'instance' I mean something that enables the enjoyment of the features specified by the type. In the case of ordinary types such as flags or poems, instances and tokens coincide. Conversely, in the case of fictional characters, there actually are only instances, namely mental files, that allow the enjoyment of the features specified by the type through a purported reference to an individual that exhibits these features, namely a purported token. In other words, the fictional character is instantiated by a mental file that elicits a phenomenology as of reference to a purported token from a suitable recipient of the

13 Robin Jeshion, 'Singular thought: Acquaintance, semantic instrumentalism, and cognitivism', in Jeshion, R. (ed.), New Essays on Singular Thought (Oxford: Oxford University Press, 2010) 131. 
work of fiction: 'The thought fails to have a singular content, though phenomenologically it feels as if it had a singular content'. ${ }^{14}$

To sum up, while types such as poems or flags are directly instantiated by their tokens, the specificity of fictional characters is to be instantiated by actual mental files that point to purported tokens. The purported tokens exhibit the features specified by the type, but it is in fact the mental file that enables the enjoyment of these features on the part of a suitable recipient of the work of fiction.

The relevant mental files for the process of instantiation of fictional characters belong to the category that François Recanati calls 'public files', that is, 'files shared by distinct individuals in a community' $(2012,205) .{ }^{15}$ A file that purports to refer to a certain fictional person is public since the core information to be stored in it is not arbitrarily established by its owner, nor depends on her particular perspective on the object the file is about. Instead, the relevant information is determined by a publicly accessible source, namely the work of fiction. In this sense, the file is shared by all suitable recipients of that work of fiction.

More generally, given a public mental file $(M F)$, I can open my private mental file $\left(M F_{1}\right)$ and you can open your private mental file $\left(M F_{2}\right)$. However, both our private files will purport to refer to the same object, and we will be both committed to storing in our private files the same core information about that object. This is why $M F_{1}$ and $M F_{2}$ can be traced back to a unique public file,

14 François Recanati, 'Mental Files: Replies to my Critics', Disputatio, 36, (2013), §1. Ultimately, what makes the instantiation possible is that there is such thing as purporting to refer to a merely intentional object; that is something that any theory of reference and intentionality must account for. The reason why I prefer to account for this in terms of mental files is that they trace back reference and intentionality to mental particulars, which can effectively play the role of instances.

15 François Recanati, Mental Files (Oxford: Oxford University Press, 2012). 
$M F$, which functions as a norm by which private mental files ought to abide. Just as the private mental file is the information we take to be about a singular individual, so the public mental file is the information we ought to take to be about a singular individual (and that we actually take to be so, if we behave as suitable recipients).

The public file, so understood, can be seen as a development of Geach's notion of intentional identity: 'We have intentional identity when a number of people, or one person on different occasions, have attitudes with a common focus, whether or not there actually is something at that focus'. ${ }^{16}$ However, the notion of a public file (at least as understood in this paper) requires not only that the attitudes have a common focus, but also that they ascribe the same core information to the object that is, or is purported to be, at that focus.

In the case of a fictional individual, the core information is constituted by all the features unequivocally ascribed to that individual by the work of fiction in which it appears. ${ }^{17} \mathrm{I}$ am assuming here that within a cultural practice there is significant agreement as to the features that a certain work of fiction unequivocally ascribes to a certain fictional individual. I believe that this assumption reflects a basic trait of our cultural practices. ${ }^{18}$

16 Peter T. Geach, 'Intentional identity', The Journal of Philosophy, 64, 20 (1967), 627. I want to thank the anonymous referee for leading me to clarify the notion of 'public file' by linking it to the notions of 'intentional identity' and 'suitable recipient'.

17 I use the adverb 'unequivocally' in order to rule out the features of a fictional character that a work leaves undetermined or open to a more or less arbitrary interpretation. For example 'having been transformed into a vermin' is an unequivocal feature of the fictional character Gregor Samsa whereas 'having been transformed into a beetle' is not (according to some interpretation of Kafka’s Metamorphosis, Gregor has been transformed into a cockroach).

18 This is a point that, here, I simply assume, thereby trying to articulate it in terms of types, tokens and mental files. Arguing for this very point is beyond the scope of this paper. For a thorough 
The notion of a public file leads us to the notion of a suitable recipient of a work of fiction, i.e. a recipient who stores in her mental files concerning fictional individuals precisely the core information specified by that work of fiction. Thus, in the case of a work of fiction, the public files can be conceived of as the mental files deployed by the suitable recipient of that work.

The public mental file enables the instantiation of the fictional character understood as a type, i.e. as a principle of construction of like fictional individuals. More specifically, the public mental file generated by a certain work of fiction allows the suitable recipient of this work to purport to refer to a fictional individual whose features comply with the specification established by the type. Although there is not a concrete token in the actual world, the fictional character is instantiated by a mental file that allows the suitable recipient to enjoy a purported token. Ultimately, the public mental file is the link between the type as a principle of construction that holds in the actual world and the token as an inhabitant of the fictional world, i.e. the spatiotemporal framework in which the suitable recipient of a work of fiction locates the events of the story told by this work.

The present account allows us to explain an interesting phenomenon regarding the individuation of fictional individuals, namely, the fact that sometimes the very same individual occurs at different works of fiction but sometimes different works involve different fictional individuals that token the same fictional character. A new instantiation of a pre-existing fictional character occurs when the suitable recipient of fiction is required to open a new mental file instead of recalling the mental file in which she previously stored information about a token of this character. For example, the suitable spectator of Gus Van Sant's 1999 film Psycho should open a new file about the fictional individual Norman Bates instead of retrieving the file that he or she originally created while watching Alfred Hitchcock's 1960 Psycho. Indeed, a spectator who stored information about Van Sant's Bates in the same mental file in which she previously stored

account of the grounding of the works' normativity in cultural practices' see Lamarque, Work and Object. 
information about Hitchcock's Bates would be completely misunderstanding Van Sant's Psycho arguably, she would enjoy it as a weird story about a man who disguises himself not only as his mother, but also as another man. That is why Van Sant's film produces a new token of the type NORMAN BATES - a new fictional individual numerically distinct from the one Hitchcock's film is about. By contrast, a suitable spectator of James Cameron's 1982 film Aliens should not open a new mental file about the fictional individual Ellen Ripley, but rather retrieve the file that he or she originally created while watching Ridley Scott's 1979 film Alien. In this case, Cameron's film Aliens does not create any new token of the type ELLEN RIPLEY, but just exploits a previous token.

Thus, there are two different ways in which an already existing fictional character can be imported into a new work of fiction; either by instantiating a new token (the Bates case) or by exploiting a previous token (the Ripley case). Let us call the former 'type importation' and the latter 'token importation'. This distinction, on which our file model allows us to shed some light, is usually overlooked in the debate about importation of fictional characters, yet plays a significant role in cultural practices of fiction appreciation. For example, this distinction usually underlies the distinction between a sequel, in which the token of a certain character is imported (token importation), and a reboot, in which a new token of a certain character type is instantiated (type importation).

Interestingly, the feedback (see $\S 1$ ) of the work of fiction that imports a character on the fictional character itself is different depending on the kind of importation. On the one hand, in type importation, the new work of fiction can introduce new features of the fictional character in a disjunctive manner, inasmuch as the possible successive instances shall take into account either the old features or the new ones. On the other hand, in token importation, the new work of fiction introduces new features of the fictional character in a conjunctive manner, inasmuch as the possible successive instances shall take into account both the old features and the new ones. Token 
importation is normally at work in cinematic sequels such as the Alien saga as well as in TV series, whereas type importation can be found in adaptations, remakes and reboots.

Finally, it is worth noting that the dependence relation between mental files and the individuals to whom they refer is inverted in the case of fiction with respect to the case of reality. In the latter, we open a new mental file because we encounter a new real person, whereas in the former we encounter a new fictional person because we are required to open a new mental file. This inversion of the dependence relation occurs because fictional individuals, unlike real ones, do not exist file-independently. Both are intentional objects of corresponding files, but only fictional individuals are merely-intentional objects, i.e., are nothing but intentional objects. A fictional individual is nothing but the purported reference of the mental files generated by a certain work of fiction. When a work of fiction prescribes to create a new mental file for a pre-existing fictional character $C$ (instead of prescribing to retrieve a file about a former token of $C$ ), a new token of $C$ is produced through the creation of the mental file.

The inversion of the dependence relation between mental files and the individuals they are about helps us to understand why fictional characters, unlike real people, can have multiple instances. In the case of a real person, the mental file is just a cognitive device that allows us to track the person, or have 'an epistemically rewarding relation' to this person. ${ }^{19}$ By contrast, in the case of a fictional character, the mental file is a sort of ontological device, as it were, that leads to the instantiation of the type. Therefore, if a suitable recipient of fiction creates a new file, a new instantiation of a fictional character is carried out.

Real individuals, unlike fictional characters, are not types. At most, a type can stem from a real person if he or she is imported into a work of fiction. In this case, the suitable recipient of fiction should open a new file in which to store information about this person as an inhabitant of a fictional world. Thus, the real person imported into fiction can be associated with a peculiar type,

19 Recanati, Mental Files, 20. 
which has one token in the real world and one token in the fictional world. For example, by importing Glenn Gould in the novel Der Untergeher, Thomas Bernhard created a type GLENN GOULD, which is 'tokened' (scare quotes, as I shall explain in what follows) in the actual world by a genuine particular on which mental files depend, and is tokened in the fictional world of Der Untergeher by a purported token, which depends on mental files.

That being the case, the type-token model provides us with a unified account of importation of both fictional characters and real individuals into works of fiction. This is an important explanatory advantage of the model, which allows us to clarify what it is to be the 'fictional surrogate' of a real individual. ${ }^{20}$ With respect to both fictional characters and real individuals, importation amounts to the construction of a new purported token through the opening of a new mental file on the part of the suitable recipient of the work of fiction. But there is also an important difference to be highlighted. In the importation of a fictional character, the latter already exists as a type having at least one purported token, and a new purported token is constructed (with a possible feedback on the type itself). Instead, in the importation of a real individual, it is the importation itself that creates the fictional character as a type that has a proper (purported) token in the fictional world and an improper (real) token in the real world. For example, Glenn Gould can be associated with a type, namely GLENN GOULD, which has a proper token in the fictional world of Der Untergeher and an improper token in the real world. I call the latter token 'improper' since it can be seen as a token

20 I am drawing here on the idea that the importation of a real individual into a work of fiction amounts to the creation of a new fictional individual, namely a 'fictional surrogate' of the real individual. See Andrea Bonomi, 'Fictional Contexts', in P. Bouquet et al. (eds.), Perspectives on Contexts (Stanford: CSLI Publications, 2008), 215-250; Peter Lamarque and Stein H. Olsen, Truth, Fiction, and Literature (Oxford: Clarendon Press, 1994), 126 and 293; Alberto Voltolini, 'Probably the Charterhouse of Parma Does Not Exist, Possibly Not Even That Parma', Humana.Mente, 25, (2013), 235-261. 
from the perspective of a recipient of the work of fiction, but it is not properly a token. That is because its existence is ontologically independent from that of the type.

It is worth noting that the token that fits better with the specification of the type is the proper (purported) token, not the improper (real) one. For example, the token that fits better with the features of the type GLENN GOULD specified by Der Untergeher is the fictional individual called 'Glenn Gould' in the novel, not the real Glenn Gould. From this perspective, the improper (real) token can be treated as an incorrect or defective instantiation of the type that is correctly instantiated by the proper (purported) token. Such an incorrectness allows us to estimate the accuracy of the work of fiction with respect to the real individual who has been imported. The lower the incorrectness of the improper (real) token with respect to the type, the higher the accuracy of the proper (purported) token with respect to reality.

\section{The uniqueness issue}

So far, I have argued that fictional characters such as Batman can be treated as types since they function as principles of construction of like fictional individuals in distinct fictional worlds. ${ }^{21}$ But what about a fictional character that appears only in one work of fiction, and therefore only in one fictional world? Let us consider the case of Finn Hudson, a fictional character played by the actor Cory Monteith in the TV series Glee. When Monteith suddenly died, on July 13, 2013, the author of Glee, Ryan Murphy, decided that Finn would also die in the fictional world. In this case it seems that the fictional character Finn Hudson has just one purported token, which is inextricably connected to Cory Monteith's performance.

I argue that having just one token does not prevent an entity from being a type. Indeed, a principle of construction of like things remains a principle of construction of like things even if in

21 As said above, I understand a fictional world as the spatiotemporal framework in which the suitable recipient of a work of fiction locates the events of the story told by this work. 
fact it is used only to construct one thing. By adapting a term from artistic printmaking, I will call 'monotypes' the fictional characters that in fact have just one token. As David Davies points out, in artistic printmaking we can find works that in principle might be used to produce several tokens but are actually used to produce only one token: 'The status of monotypes as singular artworks might also be thought to depend upon how they are treated in our artistic practice'. ${ }^{22}$ Likewise, I argue, the status of fictional characters as singular entities depends upon how we treat them in our cultural practices.

A fictional character such as Finn Hudson is a monotype in the sense that it actually has one token but, in principle, it might have other tokens. For example, one might write a novel in which Finn Hudson exists in a fictional world different from that of Glee, thereby leading the suitable reader of this novel to create a new mental file about Finn Hudson. In this way, a new token of the type FINN HUDSON would be generated.

The monotype character has a uniqueness that makes it resemble a real person, but it also has a fictionality that makes it resemble fictional characters that are 'pluritypes' (i.e. types having several tokens). Yet, both these resemblances also involve crucial differences. On the one hand, the monotype character differs from a real person in that the latter enjoys a self-standing existence as a particular individual in the actual world whereas the former is instantiated by a purported token in the fictional world through a public mental file produced by a work of fiction in the actual world. On the other hand, the monotype character differs from a pluritype character such as Batman since, in the actual world, the former seems to exist only as a component of a work of fiction whereas the latter exhibits a certain independence from any particular work of fiction (as a principle of construction of like fictional individuals who appear in different works of fiction).

The notion of a template can be used to clarify the distinction between a monotype character and a pluritype character. I borrow the term 'template' from Noël Carroll's account of films as

22 Davies, 'Varying Impressions', 84. 
types. ${ }^{23}$ According to Carroll, the film-template is the entity (for example a filmstrip or a sequence of digits) that allows the film-type to be instantiated in a screening. Likewise, the charactertemplate, as understood in this paper, allows a fictional character to be instantiated by a mental file whereby the suitable recipient of a work of fiction can enjoy a purported token. More specifically, I conceive of a template of a fictional character as the part of a work of fiction that is responsible for the creation of the public mental file that instantiates that character. ${ }^{24}$ In other words, a template of a fictional character is the part of a work of fiction that determines the core information that the suitable recipient of that work should store in the mental file about the purported token of that character (see $\S 2$ ). While the type governs the construction, by fiction-makers, of like fictional individuals who appear in different works of fiction, the template governs the construction, by the suitable recipient of a work of fiction, of a certain fictional individual who appears in that work of fiction.

A monotype character has just one template, whereas a pluritype character has different templates, one in each distinct work of fiction. In other words, a pluritype character generates distinct purported tokens through distinct templates. In this sense, the monotype entirely owes its normativity to the work of fiction to which it contributes. By contrast, a pluritype enjoys a normativity of its own that spreads across several works of fiction.

However, each monotype potentially is a pluritype inasmuch as the features it specifies

23 Noël Carroll, Theorizing the Moving Image (Cambridge: Cambridge University Press, 1996), 67.

Thanks to the anonymous referee for leading me to clarify the functioning of the template in the case of fictional characters.

24 The relation that holds between the template and the purported token of a fictional character might be compared to the relation that holds between the genotype and the phenotype of a biological individual. In both cases, the former element (template/genotype) determines the appearance of the latter (purported token/phenotype). 
through a template in a certain work of fiction might be used to construct other templates as components of other works of fiction - and therefore other purported tokens. Although the normative content of the monotype coincides with that of the template through which the monotype is instantiated, the monotype and the template remain distinct entities. That is because, as noted, the monotype governs the possible construction (by fiction-makers) of like fictional individuals whereas the template governs the construction (by the suitable recipient of a work of fiction) of a certain fictional individual.

A monotype turns into a pluritype when it is actually used to construct a new template as a component of a distinct work of fiction that leads to the construction of a new purported token. Batman itself was a monotype when it was originally created by Kane in 1939. It became a pluritype only when it was used as a principle of construction of a new purported token (arguably in 1943, when the first Batman TV series was released).

The phenomenon of adaptation is often crucial in order to turn a monotype character into a pluritype. Fictional characters in books or comics can become pluritypes by means of an adaptation in a film or in a TV series. Symmetrically, a character in a film or in a TV series may become a pluritype by means of literary adaptations, as nowadays often happens in so-called 'fan fictions' ${ }^{25}$ Finally, it is worth highlighting the distinction between literature and cinema, on the one hand, and theatre, on the other. In forms of art such as literature or cinema, a fictional character may be created as a monotype and then become a pluritype. By contrast, in theatre the fictional character behaves from the beginning as a pluritype inasmuch as it functions as a principle of construction of like performances for several actors (i.e. as a role).

25 A fan fiction is a fiction about characters from an original work of fiction, created by fans of that work. It has become particularly popular since the advent of the Web. 


\section{Conclusion}

In this paper, I have tried to clarify the claim that fictional characters are abstract artefacts, by arguing that fictional characters are abstract artefacts in the sense that they are types. On my account, this means they are principles of construction of like purported tokens, that is, fictional individuals to whom suitable recipients of fiction purport to refer through public mental files.

The tokening of a fictional character by a fictional individual requires the construction of a mental file, and this construction is carried out by a work of fiction. More specifically, the construction of a fictional individual is carried out by the part of a work of fiction that specifies the features of that individual. I have called this part of the work of fiction a template of the fictional character.

Usually, when a work of fiction creates a new character, the latter is initially just a monotype, which corresponds to one template, by means of which the (so far unique) purported token is generated. This (so far unique) purported token is the model particular of the fictional character. Still, even in this basic monotypical form, the fictional character remains a type, which, in principle, might be tokened by a multiplicity of fictional individuals generated by distinct templates that function as components of distinct works of fiction. When this potentiality is actually exploited, the fictional character becomes a pluritype whose normativity spreads across a multiplicity of works of fiction.

In fact, the claim that fictional characters are types is not a brand-new idea. Similar accounts were proposed, for example, by Nicholas Wolterstorff and Peter Lamarque. ${ }^{26}$ As Anthony Everett writes, 'Peter Lamarque and Nicholas Wolterstorff identify fictional characters with types-ofpeople, where we might think of these as being sets of properties or descriptive conditions' ${ }^{27}$ Still,

26 Wolterstorff, Works and Worlds of Art; Lamarque, Work and Object: Explorations in the Metaphysics of Art.

27 Anthony Everett, The Nonexistent (Oxford: Oxford University Press, 2013), 143. 
as Everett points out, a view such as Wolterstorff's or Lamarque's is a 'Platonic view' that finds it hard to explain the historicity of fictional characters. ${ }^{28}$ By contrast, in the account of fictional characters as Strawsonian types that I have proposed, types are conceived of as historical entities, not as eternal and immutable Platonic Forms. My account explains how such types can be created, instantiated and possibly modified within our cultural practices, and to that extent takes the type view a step further.

In his critical analysis of Wolterstorff's and Lamarque's accounts, Everett writes: 'I am perfectly willing to accept the existence of types-of-people. And I grant that they may sometimes play an important role in the way we think and talk about fiction. But they are not fictional characters; they are not what we talk and think about when we think about the character of Holmes or talk about Austen creating Emma' ${ }^{29}$ Ultimately, in this paper I have argued that we can conceive

28 Everett, The Nonexistent, 141. Both Wolterstorff and Lamarque try to connect the fictional character as a Platonic Form to the historical circumstances of its creation. Wolterstorff (Works and Worlds of Art, 144-145) writes 'a person-kind is not properly called a 'character' until some work has been composed of whose world it is a component'. And Lamarque: 'As characters per se, and thus types, they are not created, for sets of properties exist just to the extent that the properties themselves exist [...]. However, as fictional characters they are created, to the extent that their grounding narratives are created, and to the extent that they can be individuated in a quasi-indexical manner by pointing to the source narrative' (Work and Object: Explorations in the Metaphysics of Art, 200-201). However, in both accounts, the fictional character remains essentially tied to an eternal and immutable set of properties, namely a Platonic Form. For a fullfledged criticism of Wolterstorff's view along these lines, see Thomasson, Fiction and Metaphysics, 58-60.

29 Everett, The Nonexistent, 143, my emphasis. Everett criticizes Lamarque's and Wolterstorff's accounts in the framework of his fictionalist account of fictional characters. According to 
of types in such a way that they really are what we talk and think about when we think about the character of Holmes or talk about Austen creating Emma.

fictionalist theorists, fictional characters are nothing but things to which we pretend to refer in the games of make-believe which works of fiction provide us with. The locus classicus for fictionalism is Kendall L. Walton, Mimesis as Make-Believe (Cambridge: Harvard University Press, 1990). Indeed, fictionalism is a version of a more general view called 'antirealism', according to which fictional characters are nothing but objects of thought. For other antirealist accounts of fictional characters, see: Tim Crane, The Objects of Thought (Oxford: Oxford University Press, 2013); Stacie Friend, 'Notions of Nothing', in M. Garcia-Carpintero and G. Marti (eds.) Empty Representations (Oxford: Oxford University Press, 2014). I guess that the account of fictional characters as types that I have proposed can effectively address the objections that the supporters of fictionalism (and more generally antirealism) raise against the defenders of realism. But this shall be the topic of another paper. 